\title{
AMANTES DA BELEZA IMPERFEITA
}

\author{
Marcelo Tápia \\ Universidade de São Paulo, São Paulo, São Paulo, Brasil
}

\begin{abstract}
Resumo: No panorama da recepção e da recriação, no Brasil, de Les fleurs du mal (1857), de Charles Baudelaire, a antologia organizada e traduzida por Guilherme de Almeida (1944) permanece como fonte de reflexões sobre a tradução poética e suas relações com a afinidade e a identificação entre tradutor e autor, bem como entre suas concepções acerca de poesia. O presente artigo procura demonstrar, por meio da releitura dos apontamentos do tradutor dos poemas, seu persistente potencial iluminador sobre características da célebre obra original e a tarefa do traduzir como um diálogo convergente entre poéticas e idiomas distintos.
\end{abstract}

Palavras-chave: Baudelaire; Tradução; Guilherme de Almeida.

\section{LOVERS OF THE IMPERFECT BEAUTY}

\begin{abstract}
In the panorama of the reception and re-creation in Brazil of Les fleurs du mal (1857) by Charles Baudelaire, the anthology organized and translated by Guilherme de Almeida (1944) remains a source for reflections on poetic translation and its relations with affinity and the identification between translator and author, as well as between his conceptions about poetry. The present article seeks to demonstrate, through the rereading of the poet's translator's notes, his persistent illuminating potential on the characteristics of the notorious original work and the task of translating as a convergent dialogue between poetics and different languages.
\end{abstract}

Keywords: Baudelaire; Translation; Guilherme de Almeida.

A rica história da tradução de Les fleurs du mal (1857), de Charles Baudelaire, no Brasil - que inclui, inicialmente, a inserção de versões de alguns de seus textos em livros de poemas dos 
próprios autores, como era prática na época (este assunto voltará a ser abordado mais adiante $)^{1}$ - conta com um marco peculiar: a antologia Flores das "Flores do mal" de Charles Baudelaire, de Guilherme de Almeida, lançada em 1944 pela editora José Olympio².

A peculiaridade e a especial importância da obra decorrem não só dos resultados obtidos pelas traduções de Almeida para 21 poemas da poesia baudelairiana, ainda hoje largamente consideradas referenciais, como pelo fato de o tradutor ter incluído, no volume, notas sobre suas opções tradutórias e uma breve apresentação de suas concepções acerca do traduzir, que constituem uma referência importante na história do pensamento sobre tradução em nosso país, bem como relevantes comentários sobre a poética de Baudelaire. Por essa razão, focalizaremos, neste artigo, as concepções que emergem das relações entre a obra original e a recriação de Almeida.

\section{Florilégio das Flores}

O poeta e tradutor Guilherme de Almeida (1890-1969), um dos mentores do movimento modernista brasileiro na década de 1920 , contribuiu significativamente para a reflexão sobre tradução poética no país, e também para a divulgação, nele, da obra de poetas franceses $^{3}$. Pode ser considerado pioneiro na discussão de questões

${ }^{1}$ Traduções de poemas de Les fleurs de mal começaram a ser publicadas 14 anos após a edição do texto original, em 1872, a primeira por Carlos Ferreira, a que se seguiram nomes como Luiz Delfino, Teófilo Dias, Afonso Celso, Augusto de Lima Wenceslau de Queiroz e Olavo Bilac, entre outros, acompanhados por representantes das gerações posteriores. O livro de Baudelaire foi traduzido na íntegra por Jamil Almansur Haddad (1958), Ignácio de Souza Moitta (1971), Ivan Junqueira (1985) e Mário Laranjeira (2011).

${ }^{2} \mathrm{O}$ livro foi republicado em formato de bolso pelas Edições de Ouro, em 1965, e pela Editora 34, em 2010.

${ }^{3}$ Guilherme de Almeida publicou três volumes de traduções de poemas de autores franceses, cujas referências são as seguintes: Poetas de França (1936); Paralelamente a Paul Verlaine (1944); Flores das "Flores do mal" de Charles Baudelaire 
fundamentais sobre o tema; o termo "recriação", por exemplo, foi, entre outros, proposto por ele como alternativa, tratando-se de poesia, à palavra "tradução":

E, por isso, uma repugnância minha, invencível, pelas desmoralizadas e desmoralizantes expressões 'tradução', ou 'versão' [...] servir-me-ei de outra terminologia: 'recriação', 'reprodução', 'recomposição', 'reconstituição', 'restauração', 'transmutação', 'correspondência', etc.; e, principalmente, 'transfusão'. [...] Transfusão de sangue: a revivificação de um organismo pela infiltração de um sangue alheio, mas de 'tipo' igual. Uma língua, uma poesia reabastecendo-se da seiva de outra, análoga, para mais e melhor se afirmar. (ALMEIDA, 2010, p. 97-98)

Se a poesia francesa valeu-se do poeta modernista para seu "aportuguesamento", ele, por sua vez, serviu-se de seus poetas e poemas preferidos para não só realizar sua tarefa de tradutor, mas, também, conceituá-la e defendê-la. As observações, dedicatórias e, principalmente, notas incluídas em suas obras permitem, em conjunto, revelar sua visão acerca dos poemas e da tradução poética, assim como os procedimentos por ele utilizados, constituindo-se em importante esforço esclarecedor sobre a atividade.

Em sua apresentação a Poetas de França, Almeida afirma que traduzir versos “seria antes 'reproduzir', no sentido autêntico, primitivo do termo: 're-' 'produzir', quer dizer, produzir de novo, ou seja, sentir, pensar e dizer como o autor e com o autor". Para o tradutor, "pensar e dizer como o autor" significava saber os versos de cor, os quais, "de tão ditos e reditos, citados e recitados [...]", teriam se tornado "uma fôrma para a forma do meu próprio sen-

(1944). Realizaram-se, mais recentemente, as seguintes reedições de tais livros: Flores das Flores do Mal de Baudelaire (2010); A voz dos botequins e outros poemas (2009) (correspondente a Paralelamente a Paul Verlaine); e Poetas de França (2011).

Cad. Trad., Florianópolis, v. 38, $\mathrm{n}^{0}$ esp. Baudelaire 150 anos, p. 98-112, ago-dez, 2018 
timento e do meu pensamento próprio, até que eu me surpreendi repetindo-os como coisas minhas, na língua que é minha..." (1936, p. 21). Em sua antologia de Les fleurs du mal - obra esta que, por sua grandeza e suas características, motivou as mais significativas reflexões de Almeida sobre recriação poética - o tradutor faz afirmação semelhante sobre os poemas traduzidos ${ }^{4}$.

"Coisas minhas": esta noção fundamental prevê, ainda que por derivação, a consciência da atuação criadora do tradutor, que incluirá o diálogo com o autor do poema original, ou melhor, o diálogo entre ambos os poemas - o da língua de partida e o da língua de chegada. Dizer "com o autor" envolve a "co-laboração", o fazer conjunto, que necessariamente implica a aceitação, pelo texto original (que representa o autor), das inevitáveis transformações próprias das necessidades impostas pela "re-criação" alheia. O título Paralelamente a Paul Verlaine evidencia a conceituação do paralelismo da atividade recriadora em relação à obra de que parte: os poemas recriados serão "autônomos, porém recíprocos", no dizer posterior de Haroldo de Campos (TÁPIA; NÓBREGA, 2013).

Ainda que a ideia de autoria ou apropriação fizesse parte, por meio da prática emulatória, da história da literatura e da tradução no ocidente, é importante a explicitação do papel criador, autoral, desempenhado dentro dos limites permitidos pela pressuposta correspondência, ou pelo paralelismo, entre o poema traduzido e o poema original. Em seu artigo "Guilherme de Almeida e a tradução como forma" (2012), Álvaro Faleiros - ele mesmo uma das referências atuais, no Brasil, no campo da tradução de poesia e da teorização sobre ela -, vale-se de observações de Júlio Castañon Guimarães para assinalar a relevância histórica da obra tradutória de Guilherme de Almeida. Castañon o considera "um dos primeiros a operar de modo mais completo uma 'mudança da noção de tradução', por ter tido o cuidado de (diferentemente de alguns

4 "Versos [...] que eu sempre soube de cor e que, à força de dizê-los, citá-los e recitá-los, acabei por me surpreender ouvindo-os de mim mesmo, na minha língua mesma." (ALMEIDA, 2010, p. 97)

Cad. Trad., Florianópolis, v. 38, $\mathrm{n}^{0}$ esp. Baudelaire 150 anos, p. 98-112, ago-dez, 2018 
antecessores não muito distantes, como Alphonsus de Guimarães, que incluíam poemas traduzidos em seu próprio livro de poemas) "publicar em volumes distintos sua obra de poeta e as obras traduzidas". Se havia, tradicionalmente - particularmente entre o século XVII e o início do século XX, como assinala Castañon -, a possibilidade de modificação "livre" dos textos originais durante um processo de tradução ligado à ideia de emulação, também se pode constatar, na história da tradução poética, inclusive recente, a ideia de subserviência por meio da fidelidade da tradução ao "sentido" do original, em detrimento da necessária "fidelidade à forma" (expressão esta decantada por Haroldo de Campos, a partir das postulações de Walter Benjamin em seu famoso ensaio Die Aufgabe des Übersetzers" - "A tarefa do tradutor").

Em Flores das "Flores do mal" de Charles Baudelaire, Almeida afirma que em seu processo de "transfusão" haveria uma "espécie de entente cordiale, de tácita e recíproca sujeição" (ALMEIDA, 2010, p. 97): tal pensamento permite observar que a qualificação de "tácita e recíproca" atribuída à sujeição realiza uma equação que desfaz a diferença, instaurando a noção de igualdade, e negando, portanto, a própria sujeição, anulada pela bilateralidade. Se o produtor do texto original também se sujeita ao "re-criador", a permanência do original como algo intocado, hierarquicamente superior, dissipa-se. Em termos gerais, as noções de nutrimento pelo sangue alheio e do diálogo entre duas identidades sugerem o esvanecimento de limites e de ênfase na relação entre as criações em línguas diversas.

Como se daria, contudo, para o autor, a dita "revivificação" do "organismo" por um "sangue alheio", de "tipo igual”? Almeida buscava estabelecer, em suas recriações, correspondências rítmico-formais diretas com os textos originais; em seus comentários, observa, centralmente, características métricas, rímicas, sintáticas e fônico-semânticas dos poemas em francês, explicitando suas escolhas a elas correspondentes. No caso, por exemplo, de "Litanias de Satã", após assinalar tratar-se de "uma ladainha mesmo, com seus pregões e seu responso monocórdico", o tradutor explica a 
estrutura métrica ("um alexandrino primário, exato") do pregão, para a qual teria procurado "o mesmo efeito", e também a rímica ("parelhas de rimas graves [...] e agudas [...]"), "uma disposição simétrica" que ele teria respeitado "religiosamente".

A própria escolha do poeta quanto àquilo que deve ser ressaltado em suas notas explicita sua opção fundamental pela valorização das relações entre som e sentido. Na nota referente ao poema "A uma passante" ("À une passante"), para darmos mais um exemplo, o autor focaliza quase que exclusivamente a aliteração em " $r$ " reconstruída no verso "A rua, em torno, era ensurdecedora vaia", que nada fica a dever ao original no plano estético, talvez superando-o em sonoridade. É este, nitidamente, o caso da recriação do verso "Rien n'égale en longueur les boiteuses journées", do segundo "Spleen", para a qual o poeta diz ter descoberto uma “onomatopeia que, pela aliteração em 't', 'r' e 'p', dá bem ideia dos tropeções desses dias mancos: 'Nada é igual ao torpor desses trôpegos dias" "...

No dizer de Álvaro Faleiros,

É possível assim reconhecer, na concepção esboçada por Guilherme de Almeida, ao longo das décadas de trinta e quarenta do século $\mathrm{XX}$, parte dos princípios que regem as concepções dominantes do traduzir poemas hoje no Brasil. Essas aproximações anunciam tanto a teoria da transcriação formulada a partir dos anos 1960, principalmente por Haroldo de Campos (1976), quanto as teorias textuais formuladas de modo mais explícito a partir dos anos oitenta, principalmente por Paulo Vizioli (1985), Mário Laranjeira (1993) e Paulo Henriques Britto (2002). Essas considerações nos levam, pois, a concluir que Guilherme de Almeida é certamente precursor dessa longa e profícua tradição da tradução como forma, prática esta que modificou o estatuto da tradução poética no Brasil. (2012, p. 10-11) 


\section{Baudelaire e Almeida: afinidades}

Em sua Apresentação à edição de bolso de Flores das "Flores do Mal" - lançada em 1965 pelas Edições de Ouro -, Manuel Bandeira cita a descrição que faz Théophile Gautier do poeta. Objeto de admiração de Baudelaire e da dedicatória inscrita em seu livro, Gautier afirma que seu "ar, muito simples [...] sustentava com sangue-frio glacial alguma teoria de uma extravagância matemática, pois aplicava um método rigoroso no desenvolvimento de suas loucuras".

Bandeira relembra o fato de Baudelaire ter sofrido "da família a hostilidade à sua vocação literária", e de o poeta ter se revoltado contra a tentativa de destiná-lo ao comércio e decidido viver solitário em Paris, levando vida difícil. Para o autor, o "frisson nouveau" ("frêmito novo") atribuído por Victor Hugo a Baudelaire - que lhe vale, como aponta Bandeira, a identificação de "marco inicial da poesia moderna" -, não excluía o "mal romântico, o famoso 'mal de século', aquele tédio dos inadaptados à realidade quotidiana, aquele "vago nostálgico da alma que se consome em desejos estéreis"”.

À parte as grandes e evidentes diferenças de vida e obra entre o poeta francês e o tradutor brasileiro da antologia, diga-se, primeiramente, que a perspectiva do referido "mal romântico" faz parte do horizonte de Guilherme; segue-se uma breve abordagem do tema, que incluí no posfácio da reedição mais recente das Flores das Flores:

Nascido em 1890, e, consequentemente, advindo de uma geração parnasiano-simbolista, o poeta Guilherme revela uma afinidade profunda com o célebre autor francês - considerado o grande precursor do simbolismo -, afinidade que provém do próprio tempo por eles vivido, ou do que poderíamos chamar de 'espírito de época'; esta ligação, pela ampla circunstância, realiza-se não só pelo teor das tematizações, pelo modo de considerar a forma - a busca dedicada e atenta de construção e de lapidação -, mas 
também pela intenção de superar a regra esperada: as 'defeituosas perfeições' de Baudelaire, ou 'imperfeições' de 'perfeita poesia', são focos de interesse de Guilherme para uma 'reconstituição' (outro dos termos usados pelo poeta [para designar a tradução poética], além de 'transcrição' - no sentido em que é empregado em música, de elaboração de arranjo para instrumentos diversos daqueles para os quais uma composição fora escrita -, e de 'transmutação') do poema em língua outra. Há observância das imperfeições e admiração, coexistentes; uma espécie de conflito entre a noção de perfeição a ser buscada e de sedução pelo imperfeito que transcende a regra e cria padrões próprios. Esta dubiedade complementar está, por sinal - frise-se -, presente na obra original de Guilherme, na qual convivem o cultivo da tradição e a postura atenta às possibilidades de renovação [...] (ALMEIDA, 2010, p. 128-129)

O "espírito de época" impregna também o poeta-tradutor brasileiro, dedicado ao "rigor dos versos", mas apreciador de certo "desleixo" a ele associado, como se pode depreender de comentários seus às próprias traduções, referidos mais adiante.

Há afinidade entre ambos, também, quanto à aplicação de um "método rigoroso", sob distintos prismas, que vão da construção métrico-rítmica e rímica dos versos à procura de possibilidades de correspondência e recriação no plano de conteúdo dos textos: Almeida recorre, durante seu trabalho, ao cotejamento de diferentes edições de Les fleurs du mal, vindo a adotar as versões diversas nelas contidas como referências para algumas soluções tradutórias.

A obstinada procura do tradutor por variantes nos poemas de Baudelaire permitiu-lhe encontrar justificativa adicional para certa "infidelidade" semântica em "As litanias de Satã":

Estranha coincidência: por necessidade de rima ou por que quer que seja, fugi à letra da 'edição definitiva' num dos versos deste poema: 
'Toi qui, magiquement, assouplis les vieux os',

Que apresentei assim:

'Tu que, magicamente, abrandas como mel'.

Ora, revendo a variante da edição de 1857 , verifico que coincide com essa imagem da 'moleza do mel' a da primeira redação de Baudelaire (moleza de 'baume' e 'huile'):

'Toi qui frottes de baume et d'huile les vieux os'... (ALMEIDA, 2010, p. 125)

Tratando-se de afinidades, deve-se mencionar, no âmbito do "mal du siècle", a expressão do conceito de inadequação do artista à realidade chã, representada pelo poema $L$ 'albatros ( $O$ albatroz), em que, no dizer de Guilherme, Baudelaire definiria o poeta como "o príncipe feito para o voo alto no céu, e não para o contato baixo na terra" (idem, p. 102), comparando-o com a pesada ave:

[...]

Ce voyageur ailé, comme il est gauche et veule!

[...]

Le poète est semblable au prince des muées

[...]

Exilé sur le sol au milieu des huées,

Ses ailes de géant l'empêchent de marcher.

[...]

Que sem graça é o viajor alado em seu nimbo!

[...]

O poeta é semelhante ao príncipe da altura

[...]

Exilado no chão, em meio à corja impura,

As asas de gigante impedem-no de andar. (ibdem, p. 26-27) 
Manifesto na obra poética de Almeida, o "mal" também se revela nítido em uma crônica sua, "A escada de minha mansarda", na qual diz, sobre a escada de acesso a seu estúdio, posto no ponto mais alto de sua casa:

Jamais me arrependi de tê-la subido. Sempre me arrependi de tê-la descido. [...] Chego, pesado do dia cretino e pornográfico [...] Chego. O fardo é exaustivo. Enfrento a escada. [...] Lá, no topo, está a libertação.

E subo, contando os degraus, que vão ficando cada vez mais fáceis. E eu vou ficando cada vez mais leve. Mais fáceis... Mais leve... Mais...

Pronto!

Aqui não há leis, nem mesmo a da gravitação terrestre. [...]

(ALMEIDA, 1949, [s. p.])

Um aspecto revelador da procura de Almeida pela afinidade com Baudelaire e, por meio dela, da apropriação do poema em português, é a qualificação (justificadora) de "baudelairianas" a algumas soluções que o tradutor considera afastarem-se "um pouco da letra". Na nota relativa ao poema La vie antérieure ( $A$ noite anterior), Almeida comenta que o "desvio" (presente no segundo quarteto) "está talvez compensado por uma 'trouvaille' no primeiro verso desse mesmo quarteto: "céus imaginosos", que lhe parece uma expressão "mais baudelairiana do que a original: 'les images des cieux" (1944, p. 121).

Recriar poemas a partir da busca de identificação com seu autor faz parte, como se pode observar, do universo de compreensão da tradução poética por Almeida, explicitado também em relação a Verlaine, sua alma gêmea ("Quantas vezes, nas minhas noites boêmias,/ sentindo nossas almas irmãs gêmeas" ${ }^{\text {) }}$. Desde a Dedicatória de suas Flores das Flores, o tradutor se conduz pela replicação, em outro registro e com outro teor, da Dedicatória de Baudelaire

${ }^{5}$ ALMEIDA, 2009, p. 36. 
em seu livro ("Au poëte impecable [...] Théophile Gautier avec le sentiments de la plus profonde humilité je dédie ces fleurs maladives"): “À doce dona dos meus lábios [...] À bela e rude Língua Portuguesa com humildade e orgulho dedico estas doentias flores alheias que tentei fazer suas". Fazer a obra existir em sua própria língua como poema autônomo, com a atitude de recriá-lo ou transfundi-lo mediante o mencionado entendimento recíproco entre obra / autor e tradução / tradutor, revela-se um propósito central de Almeida. Uma das decorrências dele é o próprio conhecimento que se pode fazer da poesia de Baudelaire por meio de suas notas, que encerram uma leitura crítica dos poemas e dos modos de criação de seu autor.

Na nota referente ao poema Spleen (Lembro-me mais), o tradutor focaliza o meio pelo qual recriou o "deliberado desleixo" do poema, em que nota a ausência de esperadas consoantes de apoio nas rimas (por ele atribuída a um "intencional descaso - a dar mesmo a ideia de spleen, isto é, de indiferença e desânimo):

Em vez de meter-me a desprezar a tal consoante de apoio, que em nossa arte poética não é obrigação, senão simples capricho, resolvi corresponder a essa nonchalance de Baudelaire, mantendo, de princípio a fim, apenas a rima grave - a mais fácil em português. Fica, assim, uma coisa pela outra. (ibdem, p. 116)

Seu comentário sobre o poema "Bénédiction" evoca, mais uma vez, o compartilhamento da visão do que seja o poeta, e o diálogo que busca manter com o autor:

O julgamento do Poeta. Um júri completo: o libelo materno, a acusação burguesa, a defesa angélica e a absolvição divina. Página cuja falta, em qualquer seleção das Flores do mal, seria, pelo menos, uma traição a Baudelaire e a todos os Poetas. (ibdem, p. 99) 
A busca de correspondência semântica é alargada por uma identificação como criador: segundo Almeida,

'Bénédiction' não é <bênção' para o espírito deste poema. [...] $\mathrm{Na}$ alma e no corpo, isto é, no fundo e na forma, a palavra nossa para 'bénédiction' é ‘bendição'. É termo caduco? Os dicionários comuns não o registam? - Ele existe, porém, na língua em estado latente. [...]

'Bénédiction' resume, tecnicamente, a poesia baudelairiana, com todas as suas defeituosas perfeições [...]. (ibdem, p. 99)

A ideia de "defeituosas perfeições", na perspectiva da definição de um método rigoroso de correspondência e recriação, parece servir a Guilherme de Almeida em sua busca de transfusão poética, de infiltração de sangue alheio, incorporado como fonte de nova originalidade.

Ao se colocar em posição correspondente ao do autor, o tradutor torna-se um leitor e parceiro crítico - em diálogo por meio da referida "entente cordiale" -, marcado por uma especial "sinceridade":

Daí - porque não houve imposições no escolher, nem conflito no transfundir - talvez o único mérito desta obra: o da simples sinceridade. (ibdem, p. 97)

(Tal condição não excluirá, certamente, a noção de "leitor hipócrita" ("hypocrite lecteur"), à semelhança do próprio autor, seu "irmão"...)

Nos apontamentos ao poema La beauté ( $A$ beleza), Almeida volta a se referir a uma "honrosa imperfeição":

Uma imperfeição que é um dos caprichos típicos da poesia de Baudelaire: a inobservância, nos sonetos, das duas rimas 
únicas, obrigatórias, nos quartetos; e o gosto (eu ia escrever 'mania'...) de emparelhar a rima no fecho [...]

E, também por capricho, respeitei, desta vez, o imbricado dos sons graves e agudos. (ibdem, p. 104)

Faz parte da assunção do recriar baudelairiano a permissividade de gerar "sobrecompensações", na terminologia de José Paulo Paes (1990, p. 39), como no poema La chevelure (A cabeleira):

Gostei, então, de haver encontrado para

'De l'huile de coco, du musc et du goudron'

esse

‘Um vago óleo de coro, almíscar e alcatrão’,

no qual o artigo radical árabe ('al') acrescenta maior luxo e languidez à ideia e à música do verso. (ALMEIDA, 2010, p. 107)

Permissividade essa que se inscreve em outros diversos pontos da tradução - como em Remorso póstumo (Remords posthume), aqui mencionado, por fim: "[...] na substituição de 'imparfaite' por "incompleta, terá havido traição?... Ou uma hermenêutica perfurante do verdadeiro pensamento do poeta?..." (ibdem, p. 110)

Como - assim espero - foi possível observar neste artigo, a jornada de tradução e recepção de Charles Baudelaire no Brasil foi palco de um exercício que, embora realizado com apenas 21 poemas de Les fleurs de mal, inscreve-se como raro caso de coerência entre o modo de identificação de características da obra (e do autor) - visando à correspondência no fazer poético - e a realização tradutória. 


\section{Referências}

ALMEIDA, G. Poetas de França. São Paulo: Babel Editora. 1936.

. Paralelamente a Paul Verlaine. São Paulo: Martins, 1944.

. Flores das "Flores do mal" de Charles Baudelaire. Rio de Janeiro: José Olympio, 1944.

2010 .

. Flores das Flores do Mal de Baudelaire. 3. ed. São Paulo: Editora 34,

. A voz dos botequins e outros poemas. São Paulo: Hedra, 2009. (Correspondente a Paralelamente a Paul Verlaine).

. Poetas de França. São Paulo: Babel, 2011.

. Escada de minha mansarda. Diário de São Paulo - Crônicas OntemHoje-Amanhã, São Paulo, 28 de março, [s. p.], c. 1949. Disponível em: < www. casagui lhermedealmeida.org.br $>$. Acesso em: 6 out. 2017. (Banco de dados Acervo bibliográfico e hemeroteca.)

BAUDELAIRE, Charles. Les fleurs du mal. Paris: Éditions Rombaldi, 1952.

. As flores do mal. Tradução de Jamil A. Haddad. Rio de Janeiro: Difusão Européia do Livro (Difel), 1958.

. As flores do mal. Tradução de Ivan Junqueira. Rio de Janeiro: Nova Fronteira, 1985.

. As flores do mal. Tradução de Ignácio de Souza Moitta. Belém: Conselho Estadual de Cultura do Pará, 1971.

. As flores do mal. Tradução de Mário Laranjeira. São Paulo: Martin Claret, 2011.

Cad. Trad., Florianópolis, v. 38, $\mathrm{n}^{0}$ esp. Baudelaire 150 anos, p. 98-112, ago-dez, 2018 
FALEIROS, Álvaro. Guilherme de Almeida e a tradução como forma. Plaquete. São Paulo: Casa Guilherme de Almeida, 2012.

PAES, José Paulo. Tradução: a ponte necessária - Aspectos e problemas da arte do traduzir. São Paulo: Ática, 1990.

TÁPIA, Marcelo; NÓBREGA, Thelma M. (Orgs.). Haroldo de Campos Transcriação. São Paulo: Perspectiva, 2013.

Recebido em: 15/09/2018

Aceito em: 25/10/2018

Publicado em dezembro de 2018

Marcelo Tápia. Email: marcelotapia954@gmail.com

ORCID: https://orcid.org/0000-0003-1324-6440 